\title{
Redundancy of proteins in the salivary glands of Panstrongylus megistus secures prolonged procurement for blood meals ${ }^{t 3}$
}

\author{
Ana C.M. Bussacos ${ }^{a, 1}$, Ernesto S. Nakayasu ${ }^{b, 1,2}$, Mariana M. Hecht ${ }^{a}$, \\ Teresa C.F. Assumpção ${ }^{c}$, Juliana A. Parente ${ }^{d}$, Célia M.A. Soares ${ }^{d}$, Jaime M. Santana ${ }^{c}$, \\ Igor C. Almeida ${ }^{b}$, Antônio R.L. Teixeira ${ }^{a, *}$ \\ ${ }^{a}$ Chagas Disease Multidisciplinary Research Laboratory, Faculty of Medicine, University of Brasília, Federal District, Brazil \\ ${ }^{\mathrm{b}}$ The Border Biomedical Research Center, Department of Biological Sciences, University of Texas at El Paso, El Paso, Texas, United States \\ ${ }^{c}$ Host-Parasite Interface Laboratory, University of Brasília, Federal District, Brazil \\ ${ }^{d}$ Molecular Biology Laboratory, Biological Sciences Institute, Federal University of Goiás. Goiânia, Brazil
}

\section{A R T I C L E I N F O}

Available online 11 May 2011

Keywords:

Hematophagous insect

Proteomics

Transcriptomics

Lipocalin

Salivary glands

Hemostasis

\begin{abstract}
A B S T R A C T
Panstrongylus megistus, a vector for the Chagas disease parasite Trypanosoma cruzi, is a hematophagous bug widely distributed in South America. This ubiquitous triatomine is known to colonize different wild life habitats. Additionally, P. megistus synanthropy, preying upon mammals, birds, reptiles, and eventually being predators upon insect's hemolymph probably increases its ability to survive after prolonged fasting. It was suspected that the P. megistus mechanisms of adaptation to survival might include a salivary gland complex tool-box with a diversity of pharmacologically active proteins for obtaining blood meals. Herein we describe comprehensive proteome and transcriptome of the P. megistus salivary gland. The proteomic analysis led to the identification of 159 proteins, and the transcriptome revealed 47 complete cDNAs. A diversity of protein functions associated to blood feeding was identified. The most prevalent proteins were related to blood clotting, anti-platelet aggregation and anti-vasoconstriction activities, which correlate with the insect's ability to obtain meals from different sources. Moreover, a gene of resistance to insecticides was identified. These features augments the comprehension towards P. megistus enormous capacity to survive in adverse wild life-changing habitats.
\end{abstract}

(c) 2011 Published by Elsevier B.V.

\section{Introduction}

The cone-nosed bugs (Hemiptera: Reduviid) of the subfamily Triatominae are widespread vectors of Trypanosoma cruzi agent of Chagas disease in South America. P. megistus is historically important because it was the insect-transmitter of the protozoan parasite found in the blood of a child with an acute disease described by Dr. Carlos Chagas in 1909 [1]. Triatoma infestans,
Rhodnius prolixus and Panstrongylus megistus used to be main vectors of $\mathrm{T}$. cruzi to the human population that inhabits in the American continent. During the last 30 years there was a change with the successful insecticide dislodgment of $T$. infestans from human dwellings in the dry ecosystems. Consequently, the ubiquitous P. megistus inhabiting various ecosystems were not targeted by insecticides. Lately, the sylvatic $P$. megistus have invaded the peri-domicile [2,3] previously occupied by

\footnotetext{
The authors claim no conflict of interest.

* Corresponding author. Tel.: +55 613349 4987; fax: +55 6132734656. E-mail address: antonioteixeirarl@gmail.com (A.R.L. Teixeira).

${ }^{1}$ Both authors contributed equally to this study.

2 Present address: Pacific Northwest National Laboratory, Richland, WA.
} 
T. infestans, and now it has become an increasing threat to the health of the human populations in the hinterland. The wild-life P. Megistus, hiding away in ground burrows, birds nest, and crevices on tree barks, in different ecosystems are not susceptible to insecticide spraying and household infestations cannot be prevented. Nowadays, P. megistus are highly adapted to wildlife and to peri-domestic niches in a variety of ecosystems. With an enormous adaptability to different environments and synanthropic blood feeding, P. megistus have become the most important vector of Chagas disease in the Brazilian territory [4].

Interestingly, many authors have suggested that P. megistus blood-sucking habit appears to be a recent acquisition, because they share some morphological resemblances with both plant-sucking triatomines. In addition, P. megistus appears to have undergone morphological modifications over last two centuries, since species from different geographical areas appear to have major differences in the contents of salivary glands bioamines $[5,6]$. The evidences have suggested that the alimentary habits of this insect has changed over time, and thus the possibility exists that some factors involved in food uptake and digestion could explain its ability to survive in different habitats [7].

Regardless of its high epidemiologic importance in the transmission of Chagas disease, there is a paucity of data and information on the P. megistus salivary glands protein contents. For example, it is recognized that to counteract imposing difficulties towards the acquisition of a blood meal, $R$. prolixus [8], T. infestans[9], T. brasiliensis[10] and T. pallidipennis[11] have accumulated in their salivary glands several proteins involved in vasoconstriction, anti-platelet aggregation and coagulation. It was reported that such functional proteins appears to a much lesser extent in P. megistus salivary glands [7]. Differently, it was shown that the $P$. megistus saliva has a high content of anti-complement [12] and anticoagulant functions [13]. In this regard, there is additional interest to investigate this species salivary glands because the insect's behave suggest possible variations in the mechanisms associated to preventing blood loss during its bite.

In this study we identified 159 proteins in the salivary proteome from $P$. megistus, of which 28 proteins have known blood-feeding activities. Also, we show sequences of 47 transcripts obtained from a cDNA library from $P$. megistus salivary glands, which were co-validated with liquid chromatographytandem mass spectrometry (LC-MS/MS) technique. Furthermore, we propose that a notable redundancy of pharmacologically active proteins in the $P$. megistus salivary glands is associated with the ubiquitous behavior of this hematophagous cone-nose bug.

\section{Materials and methods}

\subsection{Triatomines and salivary glands collection}

Adult P. megistus were captured in dry savannah-like ecosystem were brought to our laboratory and reared with controlled temperature of $28{ }^{\circ} \mathrm{C}, 70 \%$ relative humidity and $12: 12 \mathrm{~h}$ light/ dark photoperiod. Fifty pairs of salivary glands were dissected from adult insects after 3, 5 and 7 days post blood-feeding in mice and placed in TRIZOL reagent (Invitrogen). For the mass spectrometry experiment we collected 50 pairs of salivary glands of adults after 3,5 and 7 days after blood-feeding. The salivary glands were punctured and centrifuged at $14.000 \times \mathrm{g}$ for $5 \mathrm{~min}$, and the supernatant was collected and immediately lyophilized and stored at $-80^{\circ} \mathrm{C}$.

\section{2. cDNA library construction and transcripts analysis}

To isolated the mRNA and construct the cDNA library we used the technical procedures described on the manufacturer's protocol with some adaptations [9], using Micro-fast Track ${ }^{\text {TM }}$ mRNA isolation (Invitrogen) and SMART cDNA library construction (Clontech) kits. After obtaining the phages with expected insert cells were platted on LB/MgSO4 plates with X-gal/IPTG with $15 \mu \mathrm{l}$ cDNA library unamplified. Among $90 \%$ of the recombinants were white colonies, which were picked-up and transferred individually to $50 \mu \mathrm{l}$ of pure water. The cDNA that was amplified with different primers sets [14] were sequenced unidirectionally with PT2F3 primer and DYEnamic ET DyeTerminator Sequencing Kit (Amersham Bioscience, Piscataway, NJ, USA) using MegaBACE 1000 sequencer (Amersham Biosciences, Little Chalfont, UK). The transcripts were subjected to analysis with BLAST algorithm [15], which results were dated January, 2008. ClustalW [16], CDD [17], and TREEview software[18] were used. The transcripts were translated using the BioEdit program and the resulting polypeptide sequences were subject to phylogenetics analysis. The statistical neighbor-joining bootstrap phylogenies tests were done with de MEGA4 package [19] and Peptide Signal predicted [20].

\subsection{Mass spectrometry by LC-MS}

The P. megistus lyophilized salivary gland proteins were diluted in $200 \mu \mathrm{l}$ of HPLC grade pure-water (Sigma), and $10 \mu \mathrm{l}$ of the solution was dried-out in a speed vac and redisolved in $40 \mu \mathrm{l}$ $400 \mathrm{mM} \mathrm{NH}_{4} \mathrm{HCO}_{3}$ containing $8 \mathrm{M}$ urea. The sample was then reduced with $5 \mathrm{mM}$ dithiothreitol (DTT) for $15 \mathrm{~min}$ at $50^{\circ} \mathrm{C}$, alkylated with iodacetamide $100 \mathrm{mM}$ for $15 \mathrm{~min}$ at room temperature, and protected from the light. The sample was diluted to $1 \mathrm{M}$ urea final concentration and mixed with $4 \mu \mathrm{g}$ of trypsin (Modified sequencing grade trypsin, Promega), and the digestion proceeded overnight at $37^{\circ} \mathrm{C}$. The samples that were desalted with a lab manufactured reverse phase ziptip (POROS R2-50 resin, Applied Biosystem) [21] and submitted to fractionation in a strong-cation exchange ziptip (POROS HS50, Applied Biosystems, Framingan, MA) were eluted with an increasing concentration of $\mathrm{NaCl}(0,10,20,40,60,80,100$, and 150, 200 and $500 \mathrm{mM}$ ) [22]. After desalinization, each fraction was submitted to liquid chromatography mass spectrometry (LC-MS) analysis. The peptides were dissolved in $10 \mu \mathrm{l} 0.05 \%$ formic acid and separated in a nanoHPLC system (1D plus, Eksigent, Dublin, CA) and analyzed by an eletrospray linear ion trap mass spectrometer (LTQ XL ${ }^{\mathrm{TM}}$, ThermoFisher Scientific, San Jose, CA) as previously described [22]. At first the raw data were converted to DTA files by BioWorks version 3.3.1 software (ThermoFisher Scientific) with the following parameters: threshold 10 counts, at least 15 ions and precursor mass range from 600 to $3500 \mathrm{Da}$. The DTA files were submitted to analysis using TurboSequest (Bioworks 3.3.1, ThermoFisher Scientific, San Jose, CA) [23] algorithm against the NCBInr database (downloaded on February 
14, 2007), and considering 2.0 Da as precursor ion tolerance, cysteine carbamidomethylation and methionine oxidation as fixed and variable modifications, respectively. After the database search analyses the following filters were applied: distinct peptides (for exclusion of redundant hits); $\mathrm{DCn} \geq 0.1$; protein probability $\leq 1 \times 10^{-3}$; and $X$ corr $\geq 1.5,2.2$, and 2.7 for singly, doubly, and triply charged peptides, respectively. Then we performed a second analysis with another database which included (i) Triatoma, Panstrongylus and Rhodnius protein sequences from GenBank (downloaded on November 15, 2007); (ii) translated transcripts from the cDNA libraries from P. megistus, R. brethesi, R. robustus and T. infestans[9]; (iii) sequences from matches from the first analysis against NCBInr; and (iv) randomly generated protein sequences $(100 \mathrm{~K})$, used as false-positive entries (for calculating the false-discovery rate). The false-discovery rate was calculated to be $1.8 \%$ [22].

\section{Results and discussion}

\subsection{ESTs sequences}

The unidirectional sequencing of 47 transcripts of $P$. megistus cDNA library showed the presence of expected housekeeping genes such as elongation factors, ribosomal proteins, and translation initiation factors (Supplementary Table 1). We also found several new transcripts that matched described proteins with unknown function; one of these transcripts (GenBank accession number: 57657798) showing a signal peptide appears to indicate that a putative protein is probably secreted in the salivary gland lumen possibly during the blood feeding (Supplmentary Table 1). Besides, we found two secreted peptides previously described in T. brasiliensis[10] and $T$. infestans [9], and a hypothetical protein was also found with similarity to a T. infestans derived peptide. Altogether, the transcripts deduced proteins with blood-feeding functions comprised mostly lipocalins, pallidipins, triabins and triatins (Table 1).

\subsection{LC-MS analysis}

Proteome technology has been used to generate information for understanding the complexity of the salivary secreted proteins that play a role in the insect adaption to bloodfeeding [8]. The T. infestans salivary glands proteome was carried out with basis on two-dimensional gel electrophoresis (2-DE) and mass spectrometry approach $[9,24]$. Additionally, the comparison of results obtained by liquid chromatography and mass spectrometry with those from cDNA libraries has generated complementary knowledge about the insect's salivary gland proteins [25]. The data available from several salivary proteomes [8-10] corroborate the findings of the cDNA library sequencing. Herein, we found 20 proteins that matched with P. megistus transcriptome analysis.

The T. infestans proteomic analysis showed 200 spots in 2-DE and 58 proteins were identified, and 34 of the identified proteins were related to lipocalins and apyrases [24]. Herein we have identified 159 proteins from P. megistus salivary gland proteome (Supplementary Table 2). As expected, the majority of these sequences (64.5\%) bear similarities to saliva proteins from other insects, mostly hemiptera. Also, almost all identified saliva proteins were matched using the translated cDNA sequences from P. megistus, T. infestans and R. robustus salivary glands. Among 28 identified sequences from proteins known to be from insect's saliva, 20 matched with $P$. megistus translated cDNA sequences. Additionally, there were housekeeping proteins, such as ribosomal proteins, actin, and metabolic enzymes. These intracellular proteins appear in the saliva as apocrine secretions [26]. Consistently with our EST data, we found 28 proteins with function similarities to those of pallidipin, lipocalins, infestin (non-classical Kazal type of thrombin inhibitor) and triatin transcripts. Also, novel proteins present in the P. megistus proteome are described in Table 2.

\subsection{Features of the identified proteins}

\subsubsection{Lipocalins}

The lipocalins were the most abundant protein-encoding transcripts, which comprise almost $39 \%$ of the saliva proteins involved in blood-feeding [27]. Here, we described the presence of 10 lipocalins, including lipocalin 1 and 4, and lipocalin-like Tin66 in the transcriptome experiment. Regarding to the LC-MS part we found 14 proteins similar to triatomine (T. infestans and P. megistus) salivary lipocalins, such as lipocalin, lipocalin1, lipocalin 4, lipocalin like tin66 that were identified. Lipocalins belong to a group of small proteins with different functions, many of which are related to transport of small hydrophobic molecules, such as histamine and nitric-oxide. Their tertiary structure is highly conserved with eight-stranded antiparallel $\beta$-barrels forming a cavity with an intern ligand-binding site $[27,28]$. Lipocalins were also predominant proteins in transcriptomes of R. prolixus[8] and of T. infestans[9], attaining $84 \%$ and $55 \%$ of the predicted secreted proteins, respectively.

Also belonging to the lipocalin family, there were eight cDNA sequences of pallidipin, which is an inhibitor of collageninduced platelet aggregation [27]. Consistently, the LC-MS results showed 5 pallidipin-like proteins, which were confirmed by the P. megistus transcriptome. The pallidipin first described in T. pallidipennis[29] was shown to inhibit the platelet activation. Differently from the majority of lipocalins, pallidipin has no binding sites for small molecules. Also, other sequences related to lipocalins, such as triabin and triatin were found in the salivary gland of P. Megistus. Additionally, the P. megistus showed a thrombin inhibitor previously described in T. pallidipennis[30]. Interestingly, several sequences from $P$. megistus matched triatin from $T$. infestans.

The phylogenetic studies have shown that the lipocalin complex stems from the divergence between primary structures, which appear to result from a rapid molecular evolution rate and a possible occurrence of gene duplication [31]. In this study we pursued alignment of the lipocalins, aiming at the construction of a neighbor-joining phylogenetic-tree (Fig. 1). We observed that Panstrongylus sp. lipocalins are placed apart from those obtained from Rhodnius sp. On the other hand, P. megistus triabin and pallidipin appear to be closely related to those from T. infestans, T. brasiliensis and T. pallidipennis. Contrastingly, the P. megistus triatin appears to be different from $T$. infestans and T. brasiliensis clusters, as shown by sequence alignments (Fig. 2). Such divergence may be explained by a species-independent pallidipin allele acquisition over time. 
Table 1 - Transcripts description and function in Panstrongylus megistus salivary glands.

\begin{tabular}{|c|c|c|c|c|}
\hline Transcripts & Sequences & GenBank & Number of Clusters & Function \\
\hline \multirow{7}{*}{ Lipocalin } & Pm36 & FG589957 & 7 & Transport \\
\hline & Pm03 & FG589926 & & \\
\hline & Pm06 & FG589928 & & \\
\hline & Pm44 & FG589965 & & \\
\hline & Pm10 & FG589932 & & \\
\hline & Pm33 & FG589954 & & \\
\hline & Pm37 & FG589958 & & \\
\hline Lipocalin 1 & $\operatorname{Pm} 28$ & FG589949 & 1 & Transport \\
\hline Lipocalin 4 & $\mathrm{Pm} 07$ & FG589929 & 1 & Transport \\
\hline Lipocalin-like Tin66 & $\mathrm{Pm} 23$ & FG589944 & 1 & Transport \\
\hline \multirow[t]{3}{*}{ Pallidipin 2} & $\operatorname{Pm} 22$ & FG589943 & 3 & Antiplatelet activity \\
\hline & $\operatorname{Pm} 15$ & FG589936 & & \\
\hline & Pm08 & FG589930 & & \\
\hline \multirow[t]{5}{*}{ Pallidipin-like salivary lipocalin } & Pm39 & FG589960 & 5 & Antiplatelet activity \\
\hline & Pm41 & FG589962 & & \\
\hline & Pm30 & FG589951 & & \\
\hline & Pm26 & FG589947 & & \\
\hline & Pm38 & FG589959 & & \\
\hline Secreted kazal-type proteinase inhibitor & Pm47 & FG589968 & 1 & Vasodilator \\
\hline Triabin-like lipocalin $4 \mathrm{a}$ & $\operatorname{Pm} 14$ & FG589935 & 1 & Anticoagulation activity \\
\hline Trialysin allele & & & 1 & Pore-forming activity \\
\hline Triatin & Pm46 & FG589967 & 2 & Pore-forming activity \\
\hline \multirow[t]{2}{*}{ Triatin-like salivary lipocalin } & $\operatorname{Pm} 12$ & FG589933 & 3 & Pore-forming activity \\
\hline & Pm09 & FG589931 & & \\
\hline
\end{tabular}

\subsubsection{Kazal domains-containing peptides}

Vasodilation is a process that increases blood flow and maintains the blood circulation, and it is essential to the insect's feeding success. The Kazal domains are present in several vasodilation proteins, such as vasotab from Hybomitra bimaculata[32], rhodniin from R. prolixus[33] and infestin from

Table 2 - Proteins with blood-feeding functions found in Panstrongylus megistus proteome.

\begin{tabular}{|c|c|c|c|}
\hline $\begin{array}{l}\text { Proteins/transcript } \\
\text { sequence code }\end{array}$ & Specie & $\begin{array}{l}\text { Number of } \\
\text { isoforms }\end{array}$ & Function \\
\hline $\begin{array}{c}79 \text { kDa salivary } \\
\text { apyrase }\end{array}$ & $\mathrm{Ti}$ & 1 & $\begin{array}{l}\text { Antiplatelet } \\
\text { aggregation }\end{array}$ \\
\hline $\begin{array}{l}\text { Glutathione } \\
\text { transferase }\end{array}$ & $\mathrm{Ae}$ & 1 & Detoxification \\
\hline Infestin 1-7 precursor & $\mathrm{Ti}$ & 1 & Anticoagulant \\
\hline $\begin{array}{l}\text { Kazal-type proteinase } \\
\text { inhibitor/Pm47 }\end{array}$ & $\mathrm{Ti} ; \mathrm{Tb}$ & 2 & Vasodilator \\
\hline Lipocalin/Pm36 & $\mathrm{Ti} ; \mathrm{Pm}$ & 8 & Transport \\
\hline Lipocalin 1/Pm28 & Pm & 1 & Transport \\
\hline Lipocalin 4/Pm07 & $\mathrm{Pm}$ & 1 & Transport \\
\hline $\begin{array}{l}\text { Lipocalin-like } \\
\text { Tin66/Pm23 }\end{array}$ & $\mathrm{Pm}$ & 1 & Transport \\
\hline $\begin{array}{l}\text { Pallidipin-like } \\
\text { lipocalin/Pm39 }\end{array}$ & $\mathrm{Pm}$ & 2 & Antiplatelet activity \\
\hline Pallidipin 2/Pm22 & $\mathrm{Pm}$ & 3 & Antiplatelet activity \\
\hline $\begin{array}{c}\text { Triabin-like lipocalin } \\
\text { 4a/Pm14 }\end{array}$ & $\mathrm{Pm}$ & 1 & $\begin{array}{c}\text { Anticoagulation } \\
\text { activity }\end{array}$ \\
\hline Trialysin allele & $\mathrm{Ti}$ & 1 & $\begin{array}{l}\text { Pore-forming } \\
\text { activity }\end{array}$ \\
\hline $\begin{array}{c}\text { Triatin-like salivary } \\
\text { lipocalin/Pm12 }\end{array}$ & $\mathrm{Pm}$ & 2 & $\begin{array}{l}\text { Pore-forming } \\
\text { activity }\end{array}$ \\
\hline Salivary trypsin & $\mathrm{Ti} ; \mathrm{Tb}$ & 4 & Amidolytic activity \\
\hline
\end{tabular}

*Ae: Anopheles dirus, Ti: Triatoma infestans, Pm: Panstrongylus megistus, Tb: Triatoma brasiliensis.
T. infestans[34]. Additionally, Kazal domains proteins also have anticoagulant (rhodniin, and infestin 1 and 2) function, which depends on a conserved cysteine residues pattern, showing tridimensional conformation [35]. Infestin has two nonclassical Kazal-type domains present in six sequences coded by single gene [34], which underwent mutation and tandem duplication from a common ancestor, and post- transcriptional processing [36]. However, its post-transcriptional mechanism remains unknown. Interestingly, the rhodniin protein, which is a thrombin specific inhibitor, shows an association rate two- or three-fold higher than other Kazal domainscontaining proteins [33].

In our study, transcript sequences from the $P$. megistus salivary glands revealed $40 \%$ identity with a small $\mathrm{T}$. infestans Kazal domains-containing proteinase inhibitor, and 33\% identity with a $\mathrm{T}$. brasiliensis secreted peptide, showing vasodilator function similar to vasotab protein from the horse fly H. bimaculata[32]. However, we did not find conserved cysteine residues described in a similar protein sequence from T. infestans[9].

\subsubsection{Trialysin}

Trialysin is a $22 \mathrm{kDa}$ protein with the ability to form pores in biological membranes of prokaryotes and eukaryotes. Interestingly, its function is similar to those found in various classes of lytic molecules $[37,38]$. The trialysin is functionally similar to the antimicrobial bacterial toxins with amphypatic motif in the N-terminal region, forming an $\alpha$-helical structure with positive charges in one side and hydrophobic amino acids on the other side [37].

The alignment of $P$. megistus trialysin cDNA transcript with other related species showed 59\% similarity with trialysin from $T$. infestans. Its sequence shows a shared conserved motif comprising a small region in pro- and pre-peptide. T. infestans 


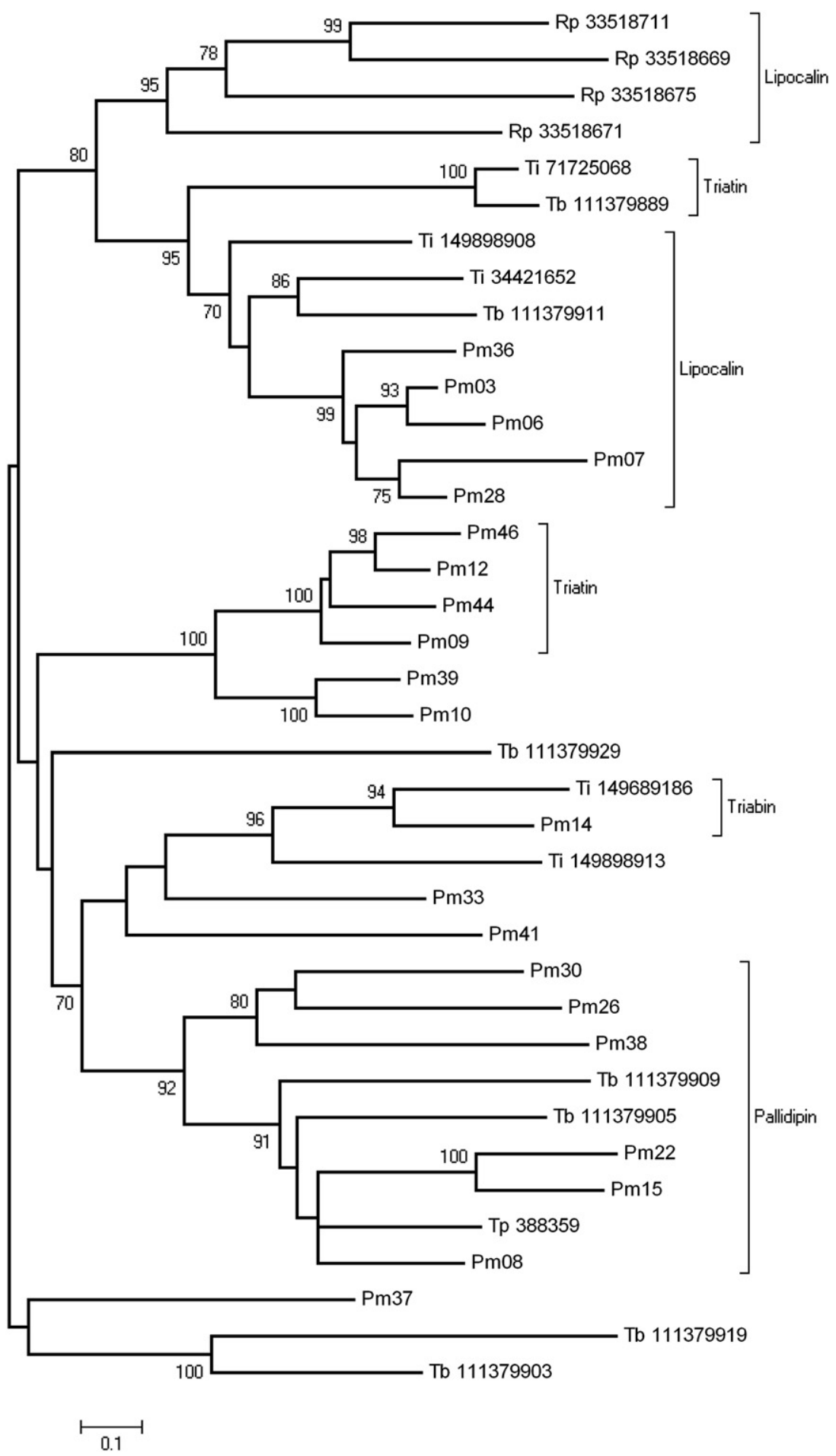

Fig. 1 - Dendogram showing convergent evolution aspects of several lipocalin family proteins from the saliva of Panstrongylus megistus (Pm), Rhodnius prolixus (Rp), Triatoma infestans (Ti), Triatoma brasiliensis (Tb) and Triatoma pallidipennis (Tp). The analysis of sequences from nonreduntant protein database of the National Center for Biotechnology Information (NCBI) were made, which are represented by the first letters of gender and specie followed by its GenBank gi number. The numbers in the dendogram nodes indicate percent bootstrap support for the phylogeny. The bar (bottom) indicates $10 \%$ amino acid divergence in the sequences. The dendogram was constructed with MEGA4 package and cut-off 70 was observed.

trialysin accumulates in the salivary gland with a pro-peptide in the N-terminal that prevents its activation, and thus inhibiting its lytic activity. Interestingly, during saliva secretion a proteolytic activity cleaves the pro-peptide thus forming a mature protein with affinity to cellular membrane. When cleavage takes place, a mature protein conformation change takes place in the $\mathrm{N}$-terminal portion enhancing its poreforming activity [38]. 

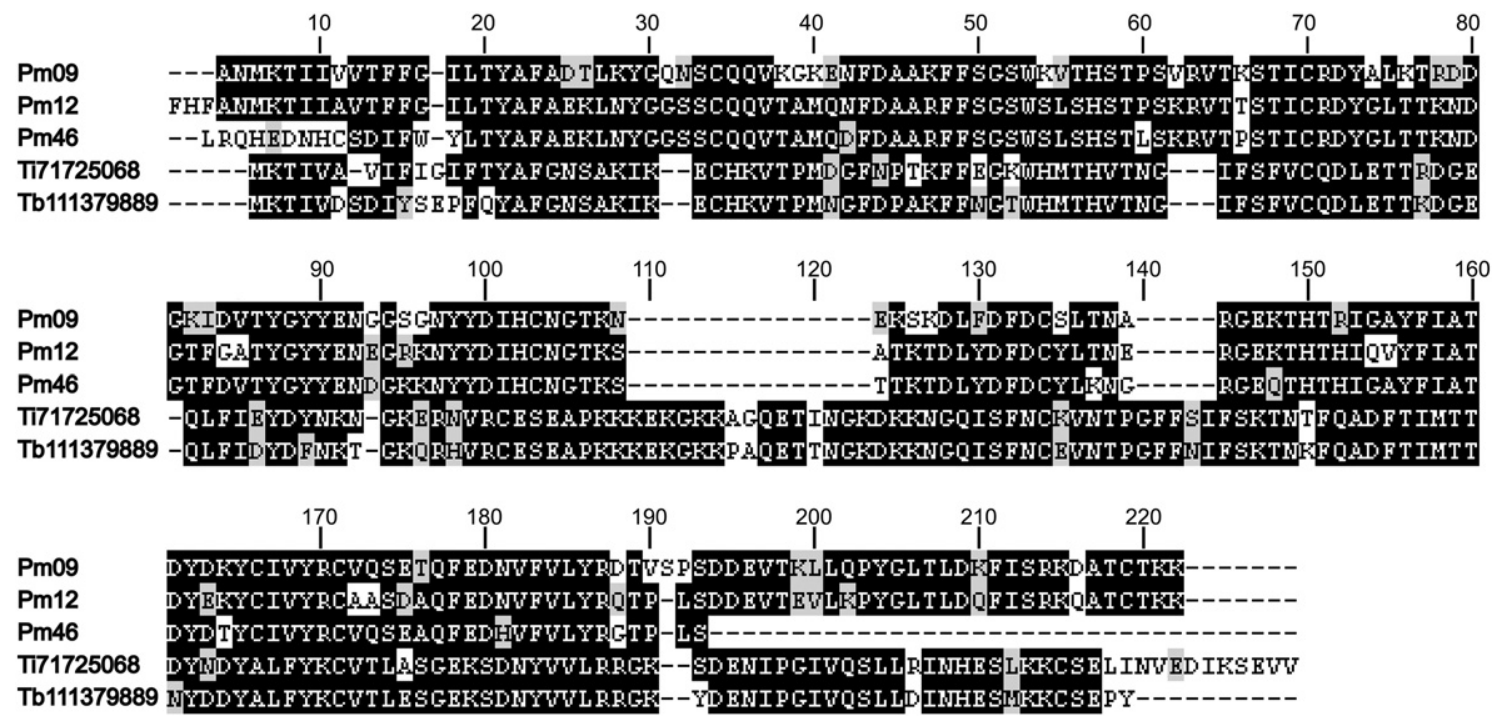

Fig. 2 - ClustalW alignment of triatin translated genes from Triatoma infestans, Triatoma brasiliensis and Panstrongylus megistus.

\subsubsection{Trypsin}

Several enzymes have been detected in P. megistus salivary glands proteome, which may play important roles during the insect's blood-feeding. We found four proteins similar to trypsin from T. infestans and T. brasiliensis. This enzyme is a serine protease similar to T. infestans triapsin, which is stored in the D2 salivary gland. Upon saliva ejection this enzyme with amidolytic function becomes active to participate in the blood-feeding process [39].

\subsubsection{Glutathione S-transferase}

The glutathione S-transferase (GST) belongs to a diverse family of enzymes. This enzyme can have multiple functions in cellular transporting, and protection against the oxidative stress. Interestingly, GST detoxicates and prevents the insect's death from insecticides. T. infestans GST is associated with resistance against DDT (1,1,1-trichloro-2,2-bis (4-chlorophenyl) ethane) [40]. In this study we show that the saliva of P. megistus has GST similar to that in the salivary glands of Anopheles dirus.

\subsubsection{Apyrase}

Platelet aggregation is essential for preventing the host's hemostasis. The insect's blood-feeding depends on the mechanism of evasion from the physical barrier posed by the platelet aggregation. Once activated, the platelet changes its conformation and releases ADP in the blood vessels, which activates and aggregates platelets. Apyrase is a nucleoside triphosphate-diphosphohydrolase capable to remove phosphate from ATP and ADP, consequently, inhibiting platelet aggregation. In the $P$. megistus saliva we found a $79 \mathrm{kDa}$ apyrase, which is also present in $T$. infestans[9,24,41,42], $T$. brasiliensis[10] and in R. prolixus[8] salivary secretions.

\section{Conclusions}

Among over 130 species of triatomines we found the ubiquitous P. megistus with an increasing participation in a complex epidemiologic chain of transmission of the T. cruzi to the human population in Latin America. To play this role P. megistus has possibly gone through a convergent evolution, whereby it accumulated a great number of pharmacologically active proteins in its salivary glands. In this study we have undertaken transcriptomics and proteomics analyses to identify the main bioamines related to this insect blood-feeding ability. This species fastidious growth in captivity used to be a bottleneck to molecular and biochemical analyses of its salivary glands. In this study, we captured the wild life P. megistus that colonized slowly in the laboratory, and obtained the insect's salivary glands to construct a cDNA library. A total of 47 transcripts revealed main proteins with vasodilation, anti-clotting, antiplatelet aggregation activities. Additionally, P. megistus proteome revealed 159 proteins, including several that showed similarities with apyrase, lipocalins, thrombin inhibitor, trialysin, trypsin and glutathione S-transferase. Overall, 9/14 protein family transcripts $(65 \%)$ were confirmed by proteomics. The main conclusion in this study is the demonstration of a complex salivary gland tool-box with elements capable to perform some functions associated with the insects' blood-feeding and resistance to insecticide. An important finding in this study is the demonstration of glutatione-S transferase gene, thus confirming field-studies reporting a substantial resistance of $P$. megistus to DTT and pyrethroids insecticides. The complementary techniques used in this study provide useful information, which are required for new insights necessary for curtailing the transmission of Chagas disease in several ecosystems. Further studies shall disclose the mechanism whereby some proteins influence the insect's behavior and adaptation to different environments, which makes P. megistus real threats to human health.

Supplementary materials related to this article can be found online at doi:10.1016/j.jprot.2011.04.028.

\section{Acknowledgements}

We thank Adriana Xavier for keeping bug's colonies in the Laboratory. ESN was partially supported by George A. Krutilek memorial scholarship, Graduate School, University of Texas at 
El Paso (UTEP). We are indebted to CAPES/MEC for a scholarship, to CNPq/MCT and FAPDF for supporting the research, and to the Biomolecule Analysis Core Facility at Border Biomedical Research Center (NIH grant \# 5G12RR008124), UTEP, where the LC-MS/MS analyses were performed.

\section{R E F E R E N C E S}

[1] Chagas C. New human trypanosomiasis. Morphology and life-cycle of Schizotrypanum cruzi, the cause of new human disease. Mem Inst Oswaldo Cruz 1909;1:159-218.

[2] Falavigna-Guilherme AL, Santana R, Pavanelli GC, Lorosa ES, Araujo SM. Triatomine infestation and vector-borne transmission of Chagas disease in northwest and central Parana, Brazil. Cad Saude Publica 2004;20:1191-200.

[3] Fernandes AJ, Chiari E, Casanova C, Dias JC, Romanha AJ. The threat of reintroduction of natural transmission of Chagas' disease in Bambui, Minas Gerais State, Brazil, due to Panstrongylus megistus. Mem Inst Oswaldo Cruz 1992;87: 285-9.

[4] Barbosa SE, Diotaiuti L, Soares RP, Pereira MH. Differences in saliva composition among three Brazilian populations of Panstrongylus megistus (Hemiptera, Reduviidae). Acta Trop 1999;72:91-8.

[5] Beard CB, Dotson EM, Pennington PM, Eichler S, Cordon-Rosales C, Durvasula RV. Bacterial symbiosis and paratransgenic control of vector-borne Chagas disease. Int J Parasitol 2001;31:621-7.

[6] Schofield C. Trypanosoma cruzi - the vector-parasite paradox. Mem Inst Oswaldo Cruz 2000;95:535-44.

[7] Barbosa SE, Diotaiuti L, Braga EM, Pereira MH. Variability of the salivary proteins of 20 Brazilian populations of Panstrongylus megistus (Hemiptera: Reduviidae: Triatominae). Acta Trop 2004;92:25-33.

[8] Ribeiro JM, Andersen J, Silva-Neto MA, Pham VM, Garfield MK, Valenzuela JG. Exploring the sialome of the blood-sucking bug Rhodnius prolixus. Insect Biochem Mol Biol 2004;34:61-79.

[9] Assumpcao TC, Francischetti IM, Andersen JF, Schwarz A, Santana JM, Ribeiro JM. An insight into the sialome of the blood-sucking bug Triatoma infestans, a vector of Chagas' disease. Insect Biochem Mol Biol 2008;38:213-32.

[10] Santos A, Ribeiro JM, Lehane MJ, Gontijo NF, Veloso AB, Sant'Anna MR, et al. The sialotranscriptome of the blood-sucking bug Triatoma brasiliensis (Hemiptera, Triatominae). Insect Biochem Mol Biol 2007;37:702-12.

[11] Haendler B, Becker A, Noeske-Jungblut C, Kratzschmar J, Donner P, Schleuning WD. Expression, purification and characterisation of recombinant pallidipin, a novel platelet aggregation inhibitor from the haematophageous triatomine bug Triatoma pallidipennis. Blood Coagul Fibrinolysis 1996;7: 183-6.

[12] Cavalcante RR, Pereira MH, Gontijo NF. Anti-complement activity in the saliva of phlebotomine sand flies and other haematophagous insects. Parasitology 2003;127:87-93.

[13] Pereira MH, Souza ME, Vargas AP, Martins MS, Penido CM, Diotaiuti L. Anticoagulant activity of Triatoma infestans and Panstrongylus megistus saliva (Hemiptera/Triatominae). Acta Trop 1996;61:255-61.

[14] Francischetti IM, Valenzuela JG, Pham VM, Garfield MK, Ribeiro JM. Toward a catalog for the transcripts and proteins (sialome) from the salivary gland of the malaria vector Anopheles gambiae. J Exp Biol 2002;205:2429-51.

[15] Altschul SF, Gish W. Local alignment statistics. Methods Enzymol 1996;266:460-80.

[16] Thompson JD, Gibson TJ, Plewniak F, Jeanmougin F, Higgins DG. The CLUSTAL_X windows interface: flexible strategies for multiple sequence alignment aided by quality analysis tools. Nucleic Acids Res 1997;25:4876-82.

[17] Marchler-Bauer A, Anderson JB, Derbyshire MK, DeWeese-Scott C, Gonzales NR, Gwadz M, et al. CDD: a conserved domain database for interactive domain family analysis. Nucleic Acids Res 2007;35:D237-40.

[18] Page RD. TreeView: an application to display phylogenetic trees on personal computers. Comput Appl Biosci 1996;12: 357-8.

[19] Tamura K, Dudley J, Nei M, Kumar S. MEGA4: Molecular Evolutionary Genetics Analysis (MEGA) software version 4.0. Mol Biol Evol 2007;24:1596-9.

[20] Bendtsen JD, Nielsen H, von Heijne G, Brunak S. Improved prediction of signal peptides: SignalP 3.0. J Mol Biol 2004;340: 783-95.

[21] Jurado JD, Rael ED, Lieb CS, Nakayasu E, Hayes WK, Bush SP, et al. Complement inactivating proteins and intraspecies venom variation in Crotalus oreganus helleri. Toxicon 2007;49:339-50.

[22] Rodrigues ML, Nakayasu ES, Oliveira DL, Nimrichter L, Nosanchuk JD, Almeida IC, et al. Extracellular vesicles produced by Cryptococcus neoformans contain protein components associated with virulence. Eukaryot Cell 2008;7:58-67.

[23] Eng JK, McCormack AL, Yates JRr. An approach to correlate tandem mass spectral data of peptides with amino acid sequences in a protein database. J Am Soc Mass Spectrom 1994;5:976-89.

[24] Charneau S, Junqueira M, Costa CM, Pires DL, Fernandes ES, Bussacos AC, et al. The saliva proteome of the blood-feeding insect Triatoma infestans is rich in platelet-aggregation inhibitors. Int J Mass Spectrom 2007;268:265-76.

[25] Mans BJ, Andersen JF, Francischetti IM, Valenzuela JG, Schwan TG, Pham VM, et al. Comparative sialomics between hard and soft ticks: implications for the evolution of blood-feeding behavior. Insect Biochem Mol Biol 2008;38:42-58.

[26] Reis MM, Meirelles RM, Soares MJ. Fine structure of the salivary glands of Triatoma infestans (Hemiptera: Reduviidae). Tissue Cell 2003;35:393-400.

[27] Assumpção TC, Alvarenga PH, Ribeiro JM, Andersen JF, Francischetti IM. Dipetalodipin, a novel multifunctional salivary lipocalin that inhibits platelet aggregation, vasoconstriction, and angiogenesis through unique binding specificity for TXA2, PGF2alpha, and 15(S)-HETE. J Biol Chem 2010;285(50):39001-12.

[28] Flower DR. The lipocalin protein family: structure and function. Biochem J 1996;318(Pt 1):1-14.

[29] Noeske-Jungblut C, Kratzschmar J, Haendler B, Alagon A, Possani L, Verhallen P, et al. An inhibitor of collagen-induced platelet aggregation from the saliva of Triatoma pallidipennis. J Biol Chem 1994;269:5050-3.

[30] Noeske-Jungblut C, Haendler B, Donner P, Alagon A, Possani L, Schleuning WD. Triabin, a highly potent exosite inhibitor of thrombin. J Biol Chem 1995;270:28629-34.

[31] Ganfornina MD, Gutierrez G, Bastiani M, Sanchez D. A phylogenetic analysis of the lipocalin protein family. Mol Biol Evol 2000;17:114-26.

[32] Takac P, Nunn MA, Meszaros J, Pechanova O, Vrbjar N, Vlasakova $\mathrm{P}$, et al. Vasotab, a vasoactive peptide from horse fly Hybomitra bimaculata (Diptera, Tabanidae) salivary glands. J Exp Biol 2006;209:343-52.

[33] Friedrich T, Kroger B, Bialojan S, Lemaire HG, Hoffken HW, Reuschenbach P, et al. A Kazal-type inhibitor with thrombin specificity from Rhodnius prolixus. J Biol Chem 1993;268: 16216-22.

[34] Campos IT, Amino R, Sampaio CA, Auerswald EA, Friedrich T, Lemaire HG, et al. Infestin, a thrombin inhibitor presents in Triatoma infestans midgut, a Chagas' disease vector: gene cloning, expression and characterization of the inhibitor. Insect Biochem Mol Biol 2002;32:991-7. 
[35] Bode W, Huber R. Natural protein proteinase inhibitors and their interaction with proteinases. Eur J Biochem 1992;204: 433-51.

[36] Lovato DV, de Campos IT Nicolau, Amino R, Tanaka AS. The full-length cDNA of anticoagulant protein infestin revealed a novel releasable Kazal domain, a neutrophil elastase inhibitor lacking anticoagulant activity. Biochimie 2006;88:673-81.

[37] Amino R, Martins RM, Procopio J, Hirata IY, Juliano MA, Schenkman S. Trialysin, a novel pore-forming protein from saliva of hematophagous insects activated by limited proteolysis. J Biol Chem 2002;277:6207-13.

[38] Martins RM, Amino R, Daghastanli KR, Cuccovia IM, Juliano MA, Schenkman S. A short proregion of trialysin, a pore-forming protein of Triatoma infestans salivary glands, controls activity by folding the N-terminal lytic motif. FEBS J 2008;275:994-1002.
[39] Amino R, Tanaka AS, Schenkman S. Triapsin, an unusual activatable serine protease from the saliva of the hematophagous vector of Chagas' disease Triatoma infestans (Hemiptera: Reduviidae). Insect Biochem Mol Biol 2001;31:465-72.

[40] Sivori JL, Casabe N, Zerba EN, Wood EJ. Induction of glutathione S-transferase activity in Triatoma infestans. Mem Inst Oswaldo Cruz 1997;92:797-802.

[41] Faudry E, Lozzi SP, Santana JM, D’Souza-Ault M, Kieffer S, Felix CR, et al. Triatoma infestans apyrases belong to the 5'-nucleotidase family. J Biol Chem 2004;279:19607-13.

[42] Assumpção TC, Charneau S, Santiago PB, Francischetti IM, Meng Z, Araújo CN, et al. Insight into the Salivary Transcriptome and Proteome of Dipetalogaster maxima. J Proteome Res 2011;10(2):669-79. 